\title{
SUPLEMENTO AL ARTÍCULO «DE LA ESTRUCTURA A LA RETÓRICA EN LA SEMIÓTICA VISUAL»
}

\section{Göran Sonesson}

\section{Lunds Universitet}

En la versión del artículo «De la estructura a la retórica en la semiótica visual», por Göran Sonesson, reproducida en Signa 5 (1996), 317 346 , faltan varios esquemas, y la numeración de las figuras ha sido cambiada. En lo que sigue se reproducen las figuras que faltan. Los números tienen que corregirse de la manera siguiente:

\begin{tabular}{|c|c|c|c|c|c|}
\hline \multicolumn{2}{|c|}{ Lugar en Signa 5} & \multirow{2}{*}{$\begin{array}{l}\text { Dice en } \\
\text { Signa } 5\end{array}$} & \multirow{2}{*}{$\begin{array}{l}\text { Otra } \\
\text { correción }\end{array}$} & \multirow{2}{*}{$\begin{array}{l}\text { Número y título } \\
\text { en el original (y } \\
\text { aquí abajo): }\end{array}$} & \multirow{2}{*}{$\begin{array}{l}\text { Reproducido } \\
\text { en Signa } \mathrm{n}^{\circ} 5 \\
\text { como }\end{array}$} \\
\hline Página & Párrafo & & & & \\
\hline 324 & 1 & fig. 1 & & $\begin{array}{l}\text { fig. 1a-b: La } \\
\text { máscara } \\
\text { Swaihwé/La } \\
\text { máscara } \\
\text { Dzonowka }\end{array}$ & $\begin{array}{l}\text { Figura } 1 \text { y } \\
\text { Figura } 2\end{array}$ \\
\hline
\end{tabular}




\begin{tabular}{|c|c|c|c|c|c|}
\hline \multicolumn{2}{|c|}{ Lugar en Signa 5} & \multirow{2}{*}{$\begin{array}{l}\text { Dice en } \\
\text { Signa } 5 \\
\text { Figura } \\
\end{array}$} & \multirow{2}{*}{$\begin{array}{l}\text { Otra } \\
\text { corrección }\end{array}$} & \multirow{2}{*}{$\begin{array}{l}\text { Número y título } \\
\text { en el original (y } \\
\text { aquí abajo): }\end{array}$} & \multirow{2}{*}{$\begin{array}{l}\text { Reproducido } \\
\text { en Signa } n^{\circ} 5 \\
\text { como }\end{array}$} \\
\hline Página & Párrafo & & & & \\
\hline 324 & 2 & fig. 2 & $\begin{array}{l}\text { Fig. } 2 \\
\text { aquí abajo }\end{array}$ & & $\begin{array}{l}\text { No } \\
\text { reproducido }\end{array}$ \\
\hline 324 & 1 & (nada) & $\begin{array}{l}\text { Falta } \\
\text { referencia }\end{array}$ & fig. 3 aquí abajo & $\begin{array}{l}\text { No } \\
\text { reproducido }\end{array}$ \\
\hline 326 & 1 & $\begin{array}{l}\text { fig. } 3 \\
\text { fig. } 4 \\
\text { fig. } 5\end{array}$ & & $\begin{array}{l}\text { fig. 4a. La } \\
\text { publicidad Kindy } \\
\text { fig. 4b. Vista } \\
\text { fija sacada de la } \\
\text { película «The } \\
\text { seven year itch» } \\
\text { fig. 4c: Poster de } \\
\text { la película «The } \\
\text { seven year itch» }\end{array}$ & $\begin{array}{l}\text { Figura } 3 \\
\text { Figura } 4 \\
\text { Figura } 5\end{array}$ \\
\hline 326 & 3 & fig. 3 & & $\begin{array}{l}\text { fig. 5a aquí } \\
\text { abajo }\end{array}$ & $\begin{array}{l}\text { No } \\
\text { reproducido }\end{array}$ \\
\hline 326 & 4 & fig. 3 & & $\begin{array}{l}\text { fig. 5b aquí } \\
\text { abajo }\end{array}$ & $\begin{array}{l}\text { No } \\
\text { reproducido }\end{array}$ \\
\hline 328 & 1 & fig. 6 & Correcto & $\begin{array}{l}\text { Fig. } 6 . \text { Tomate } \\
\text { y botella }\end{array}$ & Figura 6 \\
\hline 329 & 4 & fig. 7 & & $\begin{array}{l}\text { Fig. 7a aquí } \\
\text { abajo }\end{array}$ & $\begin{array}{l}\text { No } \\
\text { reproducido }\end{array}$ \\
\hline 329 & 5 & fig. $7 b$ & & $\begin{array}{l}\text { Fig. } 7 b \text { aquí } \\
\text { abajo }\end{array}$ & $\begin{array}{l}\text { No } \\
\text { reproducido }\end{array}$ \\
\hline 330 & 1 & fig. 7c & & $\begin{array}{l}\text { Fig. } 7 \mathrm{c} \text { aquí } \\
\text { abajo }\end{array}$ & $\begin{array}{l}\text { No } \\
\text { reproducido }\end{array}$ \\
\hline 334 & 2 & fig. 8 & & $\begin{array}{l}\text { Fig. 8: Coliseo } \\
\text { como cubo } \\
\text { para hielo }\end{array}$ & Figura 7 \\
\hline
\end{tabular}




\begin{tabular}{|rcl|}
\hline Swaihwé & vs & Dzonokwa \\
color predominante blanco & vs & color predominante negro \\
decorado con plumas & vs & decorado con pelos \\
mandíbula caída & vs & mandíbula cerrada \\
forma que impide la salida \\
boca abierta con lengua & vs & de la lengua \\
saliendo & & ojos sumidos \\
ojos saltones & vs & concavidad \\
convexidad & vs &
\end{tabular}

Fig. 2. Oposiciones en las máscaras de Lévi-Strauss.

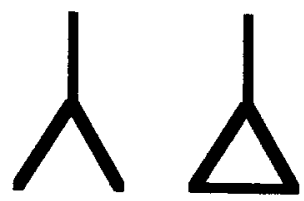

Fig. 3. Código de los aseos.

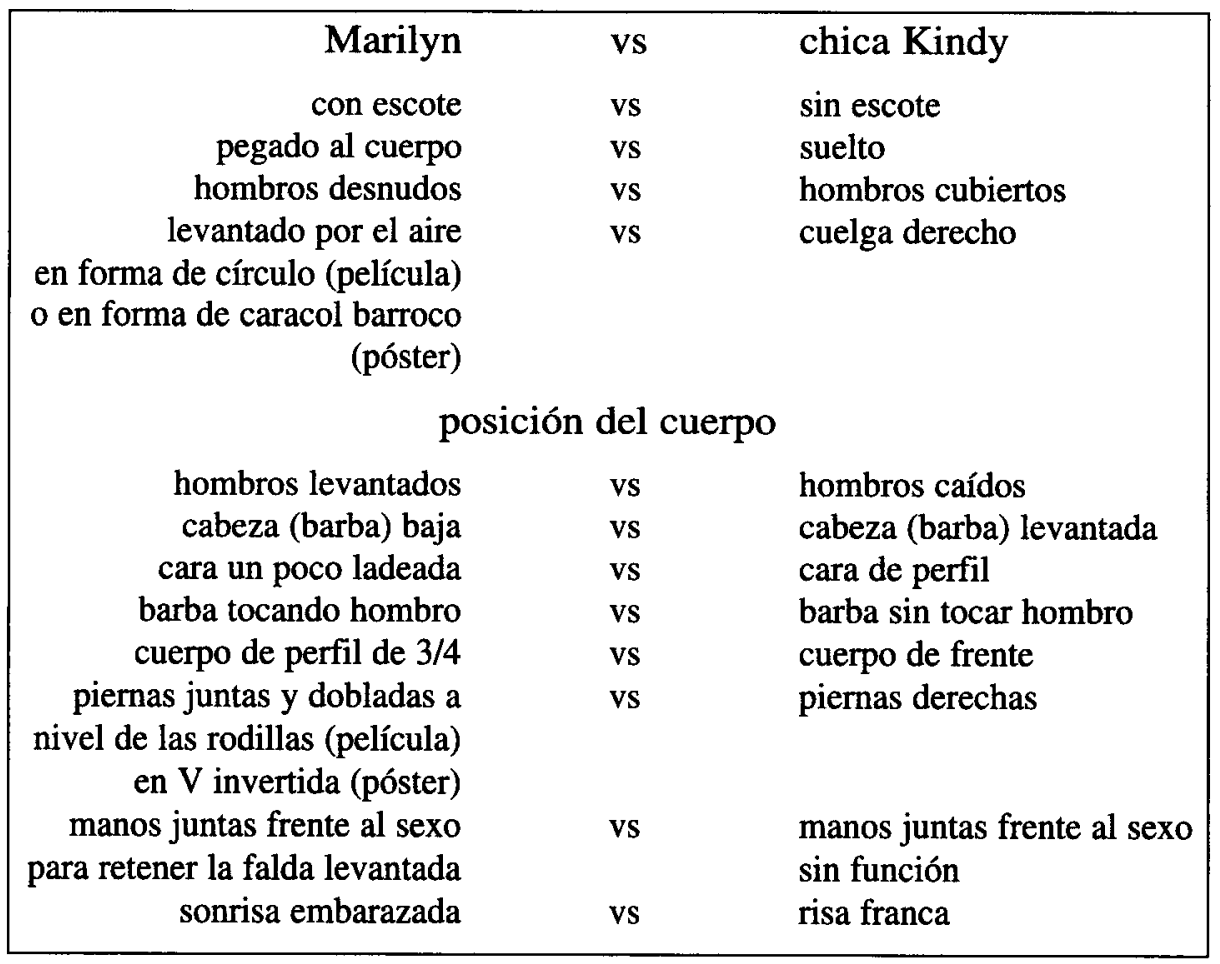

Fig. 5a. Marilyn vs Chica Kindy. 


\section{ubicación en el espacio}

un poco enfrente del hombre

vs

atrás del hombre

(película) o muy enfrente

del hombre (póster)

Fig. 5a. Marilyn vs Chica Kindy. (Continuación).

\begin{tabular}{|ccc|}
\hline Hombre con Marilyn & vs & Hombre con chica \\
posición del cuerpo & Kindy \\
espalda desde la izquierda & vs & frente y lado derecho \\
cabeza (barba) baja & vs & cabeza (barba) levantada \\
manos en los bolsillos, & & manos en los bolsillos, \\
sin función & & para levantar los pantalones \\
corbata levantada por el aire & vs & enfrente de la mujer \\
ningún efecto del aire saliendo & vs & en el espacio \\
un poco atrás de la mujer \\
(película) o muy atrás \\
de la mujer (póster)
\end{tabular}

Fig. 5b. Hombre con Marilyn vs con chica Kindy.

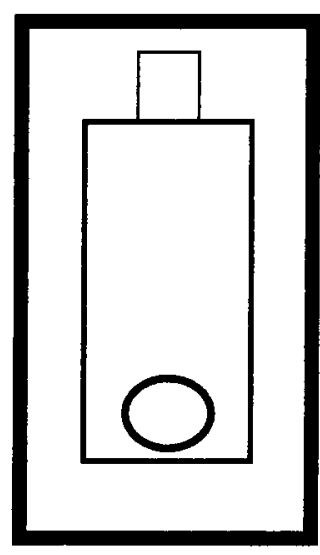

Fig. 7a. Oposiciones primarias en la imagen del tomate $y$ de la botella.

\section{a) OPOSICIONES PRIMARIAS} configuraciones

\begin{tabular}{ccc} 
círculo (A) & vs & rectángulo (B) \\
equidimensional & rasgos globales & \\
(horizontalidad predominante) & vertical \\
pequeño & vs & grande \\
redondeado & vs & angular \\
compacto & vs & contorneado \\
(brillo & vs & contorno completo) \\
peso vertical & vs & paralelismo \\
(relativamente a los límites y al espacio del texto \\
\multicolumn{3}{c}{ escrito) } \\
incluido & vs & incluyendo
\end{tabular}




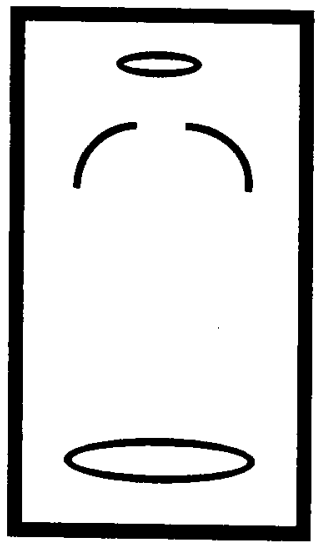

\section{b) PROPIEDADES DEL TIPO A EN B}

(o sea, propiedades características del tomate en la botella):

- gollete y orificio redondeados

- culo de la botella visiblemente redondeado

Parece que no hay propiedades del tipo $B$ en $A$ en el caso considerado (propiedades características de la botella en el tomate).

Fig. 7b. Propiedades

del tipo A en $B$ dentro de la imagen del tomate y de la botella

\section{c) PARALELISMO ENTRE A/B}

- el tomate está ubicado en el punto central de la dimensión horizontal

- hay congruencia entre el gollete y el orificio de la botella, de un lado, y el redondeado superior del tomate y sus hojas, del otro.

\section{d) MODIFICACIONES DE LAS}

\section{MODIFICACIONES:}

- el tomate sigue redondeado de la parte de abajo

- el gollete tiene líneas rectas más prominentes en la mitad de la parte redondeada

- el gollete constituye un sólo cuerpo, mientras las hojas del tomate forman tres

- el gollete apunta derecho hacia arriba, mientras las hojas del tomate marcan una dirección hacia arriba y

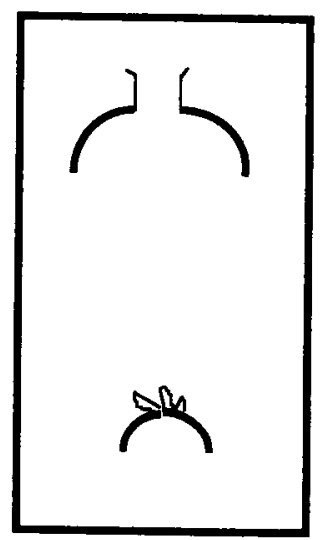

Fig. 7c. Paralelismo entre $A / B$. un poco a la izquierda.

[NOTA DE LA REDACCIÓN: Se recuerda a todos los autores de Signa que envíen sus trabajos en disquete tal como quieren que sean reproducidos en la versión impresa de la revista. Gracias.] 